\title{
RESEARCH
}

\section{DO SURGICAL PATIENTS OLDER THAN 90 YEARS MORE BENEFIT FROM INTENSIVE CARE UNIT?}

Turkish Journal of Geriatrics

DOI: $10.31086 /$ tigeri.2020.138

2020; 23(1): 60-65

n Müge ARIKAN ${ }^{1}$ (D)

CORRESPONDANCE

Müge ARIKAN

Karabük Kadın ve Çocuk Hastanesi, Anestezi ve Reanimasyon, Karabük, TURKEY.

Phone: +905053969097

e-mail: mugearikan@hotmail.com.tr

Received: 27/08/2019

Accepted: 13/12/2019

\section{Abstract}

Introduction: The number of elderly patients followed in intensive care units is increasing day by day. In the literature, there are a limited number of studies covering patients aged 90 and over. We aimed to investigate the epidemiologic characteristics and clinical outcomes of elderly patients aged $\geq 90$ years admitted to intensive care unit.

Materials and Methods: In this study, medical records of patients aged $\geq 90$ years admitted to intensive care unit, between January 2015 and January 2018, were retrospectively reviewed. Demographic data, reason for admission (medical or surgical), Acute Physical and Chronic Health Evaluation II (APACHE II) score, need for and duration of mechanical ventilation, need for inotropic agents, duration of intensive care unit stay, and mortality rate were recorded.

Results: A total of 107 nonagenarians were evaluated. The mean age of the patients was $92.65 \pm 2.36$ years, and 72 of them were women. The mean score of APHACHE II was $23.6 \pm 7.2$. Most patients were admitted due to medical reasons (n $=82,76.63 \%$ ). Sixty-four of the medical patients, and four of the surgical patients had died in the intensive care unit $(n=68,63.55 \%)$. APACHE II score, need for and the duration of mechanical ventilation, need for inotropic agents, the duration of intensive care unit stay, and the mortality rate were higher in medical patients than in surgical patients.

Conclusions: The mortality rates of the medical patients were high; nevertheless, we believe that surgical patients more benefit from intensive care unit follow-up.

Keywords: Aged; Patient; Intensive Care Unit; Mortality. 


\section{INTRODUCTION}

The world population is ageing rapidly, and according the Turkey Statistical Institute data, $0.11 \%$ of the total population was aged $\geq 90$ years in 2018 (1). In conjunction with the increase in the number of the elderly population, the number of elderly patients requiring intensive care unit (ICU) admission is on the rise. Elderly patients form an essential part of the patients admitted to ICU (2). These patients need follow-up in ICU due to acute exacerbations of existing chronic diseases or following a surgical procedure. Although nonagenarians, namely individuals aged $\geq 90$ years represent a small subgroup, they are at high risk of death. In the literature, many studies frequently evaluating patients aged 65 years or $\geq 80$ years can be found $(3,4)$. However; only a few studies on elderly patients in ICU have included nonagenarians (5-7). Therefore, this study investigated the epidemiologic characteristics and outcomes of elderly patients aged $\geq 90$ years who were admitted to ICU.

\section{MATERIALS AND METHODS}

This study was approved by the Ethics and Research Committee of Karabuk University (No:77192459050.99-E.1826). From 1 January, 2015 to 1 January, 2018 , the medical records of patients aged $\geq 90$ years admitted to the ICU of Karabuk University Hospital, Turkey, for $\geq 24 \mathrm{~h}$ were reviewed in this retrospective observational study. For patients with multiple ICU admissions, only the first admission was considered. All patients aged $<90$ years, as well as those admitted to the cardiac ICU were excluded. The ICUs of Karabuk University Training and Research Hospital are closed ICUs where patients are treated by full-time critical care physicians.

The following parameters were recorded; age, sex, comorbidities, hospital stay prior to the ICU admission, the main reason for the ICU admission (medical; respiratory, gastrointestinal, neurological, renal diseases, cardiopulmonary resuscitation, sepsis, or surgical; unscheduled or scheduled surgery), Acute Physical and Chronic Health Evaluation II (APACHE II) score on ICU admission, need for and duration of mechanical ventilation (MV), need for inotropic agents, duration of ICU stay and mortality rate.

Statistical analysis: Statistical analyses were performed using SPSS 14.0. Quantitative variables were reported as mean standard deviation (SD). Nominal variables were expressed as number and percentages. The mean data were compared using the Student's t test. Categorical data were compared using the chi-square test or Fisher's exact test upon compatibility. $\mathrm{P}<0.05$ was considered statistically significant.

\section{RESULTS}

During the three years, 3257 patients were admitted to the ICU. A total of 124 patients were aged $\geq 90$ years. Of these patients, 10 who were discharged before $24 \mathrm{~h}$ of ICU admission, and 7 with missing data were excluded. Thus, 107 (3.29\%) patients participated in the study.

The mean age of the patients was $92.65 \pm$ 2.36 years. Women comprised most of the patients $(n=72,67.29 \%)$. The mean APACHE II scores on ICU admission were $23.6 \pm 7.2$. A total of 96 (89.72\%) patients had at least one comorbid disease. The main comorbidities were systemic arterial hypertension, heart disease, diabetes mellitus, respiratory diseases, neurodegenerative disease, and chronic renal failure.

Most patients were admitted to the ICU for medical reasons ( $n=82,76.64 \%)$. Respiratory diseases (56.10\%), neurological diseases (14.63\%), and cardiopulmonary resuscitation (12.19\%) were the most frequent medical causes. 25 patients (23.36\%) were accepted for surgical reasons, of which 24\% underwent unscheduled surgery.

A total of 82 patients (76.64\%) were mechanically ventilated, and the mean MV duration was 
$9.23 \pm 2.8$ days. Moreover, 73 patients (68.22\%) patients required inotropic treatment and 8 patients (7.47\%) underwent RRT. The mean duration of ICU stay was $11.82 \pm 3.9$ days (Table 1 ). Sixty-four of the medical patients, and four of the surgical patients had died in the intensive care unit $(n=68,63.55 \%)$.

When we grouped the patients as medical and surgical, we found that the APACHE II score, need for MV, MV duration, need for inotropic agents, duration of ICU stays, and mortality rate were higher in medical patients than in surgical patients (Table 2).

\section{DISCUSSION}

In the study, nonagenarians represented approximately $3.29 \%$ of ICU admissions, and the ICU mortality rate was $63.55 \%$. Few studies have analyzed the outcome of the nonagenarians. Sim et al. examined 155 patients aged $\geq 90$ years, and reported ICU admission rates and ICU mortality rates were $0.92 \%$ and $32.3 \%$, respectively (7). Rellos et al. found that the proportion of nonagenarians in ICU was $1.1 \%$, with an ICU mortality of $20 \%$ (8). Becker et al. reported these rates as $1.1 \%$ and $18.3 \%$, respectively (6).

Table 1. Patients' general characteristics and clinical data.

\begin{tabular}{|c|c|c|}
\hline \multicolumn{2}{|l|}{ Variables } & \\
\hline \multicolumn{2}{|l|}{ Age (years), mean $\pm S D$} & $92.65 \pm 2.36$ \\
\hline \multicolumn{2}{|c|}{ Sex (female/male), n (\%) } & 72/35 (67.29/32.71) \\
\hline \multirow{7}{*}{ Comorbidities, n(\%) } & Systemic arterial hypertension & $66(61.68)$ \\
\hline & Diabetes mellitus & $42(39.25)$ \\
\hline & Heart disease & $52(48.59)$ \\
\hline & Respiratory diseases & $36(33.64)$ \\
\hline & Neurodegenerative disease & $32(29.90)$ \\
\hline & Chronic renal failure & $12(11.21)$ \\
\hline & Others & $22(20.56)$ \\
\hline \multirow{2}{*}{$\begin{array}{l}\text { Admission category } \\
\mathrm{n}(\%)\end{array}$} & Medical & $82(76.64)$ \\
\hline & Surgical & $25(23.36)$ \\
\hline \multicolumn{2}{|c|}{ APACHE II score, mean \pm SD } & $23.6 \pm 7.2$ \\
\hline \multicolumn{2}{|l|}{ Need for MV, n(\%) } & $82(76.64)$ \\
\hline \multicolumn{2}{|c|}{ Duration of MV (days), mean $\pm S D$} & $9.23 \pm 2.8$ \\
\hline \multicolumn{2}{|c|}{ Need for inotropes, $n(\%)$} & $73(68.22)$ \\
\hline \multicolumn{2}{|l|}{ Need for RRT, n(\%) } & $8(7.47)$ \\
\hline \multicolumn{2}{|c|}{ Duration of ICU stay(days), mean \pm SD } & $11.82 \pm 3.9$ \\
\hline \multicolumn{2}{|l|}{ Mortality, n(\%) } & $68(63.55)$ \\
\hline
\end{tabular}

Data are stated as mean \pm standard deviation $(m e a n \pm S D$ ) or patient number and percentage $(n, \%)$. APACHE II: Acute Physical and Chronic Health Evaluation, MV: Mechanical ventilation, RRT: Renal replacement therapy, ICU: Intensive care unit. 
Table 2. Comparison of demographic and clinical data of the medical and surgical patients.

\begin{tabular}{|c|c|c|c|}
\hline & Medical $(n=82)$ & Surgical $(n=25$ & $P$ value \\
\hline Age (years), mean $\pm S D$ & $93.68 \pm 2.8$ & $91.54 \pm 3.2$ & 0.13 \\
\hline Female sex, n (\%) & $57(69.51)$ & $15(60)$ & 0.87 \\
\hline $\begin{array}{l}\text { APACHE II score, mean } \\
\pm \text { SD }\end{array}$ & $28.48 \pm 6.1$ & $19.22 \pm 8.5$ & $<0.001^{\star *} \#$ \\
\hline Need for MV, n(\%) & $76(92.68)$ & $6(24)$ & $<0.001 \dagger \#$ \\
\hline $\begin{array}{l}\text { Duration of MV (days), } \\
\text { mean } \pm \text { SD }\end{array}$ & $11.64 \pm 2.8$ & $1.45 \pm 1.1$ & $<0.01 * \#$ \\
\hline Need for inotropes, $n(\%)$ & $68(82.92)$ & $5(20)$ & $<0.001 \dagger \#$ \\
\hline Need for RRT, n(\%) & $6(7.31)$ & $2(8)$ & 0.18 \\
\hline $\begin{array}{l}\text { Duration of ICU } \\
\text { stay(days), mean } \pm \text { SD }\end{array}$ & $14.46 \pm 2.5$ & $3.16 \pm 3.1$ & $<0.01 * \#$ \\
\hline Mortality, n(\%) & $64(78.04)$ & $4(16)$ & $<0.001 \dagger \#$ \\
\hline
\end{tabular}

Data are stated as mean \pm standard deviation (mean \pm SD) or patient number and percentage $(n, \%)$. APACHE II: Acute Physical and Chronic Health Evaluation, MV: Mechanical ventilation, RRT: Renal replacement therapy, ICU: Intensive care unit. *Student's t test, †Pearson's chi-square test, \#Statistically significant difference between groups.

Although chronological age is associated with higher rates of ICU mortality, other studies have found the severity of illness, reason for admission, and comorbidities to be more important risk factors than age itself (9-11).

The outcome of very elderly patients varies depending on the reasons for ICU admission. In previous studies, the mortality rate has been reported to be higher in medical patients than in surgical patients. Bagshaw et al. reported that after scheduled surgery, the ICU and hospital mortality rate were 12 and $25 \%$, respectively (12). Other studies have found the, rates were 38 and $64 \%$ for medical patients and 45 and $55 \%$ for unscheduled surgery patients $(9,13)$. In the present study, the ICU mortality rate was higher in medical patients $(78.04 \%)$ than in surgical patients (16\%).

Mechanical ventilation and inotropic support have been associated with mortality in patients admitted to ICU (14). In an ongoing Indian study, mechanical ventilation and inotropic support proved to increase mortality in geriatric patients (15).

Sim et al. have found that high Simplified Acute Physiology Scoring II scores, poor nutritional status, high glucose, use of vasopressors, and DNR orders should be considered as significant predictors of mortality in very elderly ICU patients (7). In a study on 104 patients aged $>85$ years, van den Noortgate et al. found inotropes as an independent risk factor in mortality (16). Orsini et al. found that advanced age, critical illness, cardiopulmonary resuscitation, and needs for mechanical ventilation and/or vasopressor therapy are independent risk factors associated with adverse outcome in elderly patients admitted to ICU (14). Similar to these results, this investigation revealed that medical patients had higher APACHE II score, need for $M V$, need for inotropes, and mortality rate.

There are noteworthy several limitations to the present study. First, this was a single-centre, non-randomised retrospective study. The longterm outcome of patients could not be assessed 
because of the retrospective nature of the study. Last, because ICU management can be different in each hospital, we cannot generalise our findings.

Although patients aged $\geq 90$ years are a small subgroup of the elderly population, their numbers are increasing. Elderly patients have high ICU mortality, but studies have shown that only age does not affect mortality. In our study, we found that the mortality rates of medical patients were high. Nev- ertheless, we believe that surgical patients benefit more from ICU follow-up.

\section{Financial Support and Conflicts of Interests:}

This report received no specific grant from any funding agency in the public, commercial, or notfor-profit sectors. The authors have no competing interests to declare regarding the publication of this paper.

\section{REFERENCES}

1. Turkish Statistical Institute. Population Projections, 2018. [Press Release]. Available from: http://web. turkstat.gov.tr/PreHaberBultenleri.do?id=30567. Accessed: 21.02.2018.

2. Bozkurt D, Kilavuz A, Ov C, Köse T, Akçiçek F. Nontraditional mortality predictors for geriatric intensive care unit patients. Turkish Journal of Geriatrics 2018;21(3):323-32.

3. Karaveli A, Cerit GN, Ozyurt E. Evaluation of admission causes and mortality rates of 65 years of age and older patients admitted from the emergency department to the intensive care unit. Turkish Journal of Geriatrics 2018;21(4):515-21.

4. Dinkci MD, Yüce $Y$, Çevil B, Erkal KH. Retrospective analysis of factors affecting intensive care unit mortality in patients over 75 years of age. Turkish Journal of Geriatrics 2017;20(2):91-9.

5. Garrouste-Orgeas M, Ruckly S, Grégoire C, et al. Treatment intensity and outcome of nonagenarians selected for admission in ICUs: a multicenter study of the Outcomerea Research Group. Ann Intensive Care 2016;6(1):31. (PMID: 27076186).

6. Becker S, Müller J, Heer G, Braune S, Fuhrmann V, Kluge S. Clinical characteristics and outcome of very elderly patients $\geq 90$ years in intensive care: a retrospective observational study. Ann Intensive Care 2015;5(1):53. (PMID:26690798).

7. Sim YS, Jung H, Shin TR, Kim DG, Park SM. Mortality and outcomes in very elderly patients 90 years of age or older admitted to the ICU. Resp Care 2015;60(3):347-55. (PMID:25406344).

8. Rellos K, Falagas ME, Vardakas KZ, Sermaides G, Michalopoulos A. Outcome of critically ill oldest-

old patients (aged 90 and older) admitted to the intensive care unit. J Am Geriatr Soc 2006;54(1):1104. (PMID:16420206).

9. Lerolle N, Trinquart L, Bornstain C, et al. Increased intensity of treatment and decreased mortality in elderly patients in an intensive care unit over a decade. Crit Care Med 2010;38(1):59-64. (PMID:19633539).

10. Ihra GC, Lehberger J, Hochrieser $H$, et al. Development of demographics and outcome of very old critically ill patients admitted to intensive care units. Intensive Care Med 2012; 38(4):620-6. (PMID:22354500).

11. Boumendil A, Maury E, Reinhard I, Luquel L, Offenstadt G, Guidet B. Prognosis of patients aged 80 years and over admitted in medical intensive care unit. Intensive Care Med 2004;30(4):647-54. (PMID:14985964).

12. Bagshaw SM, Webb SA, Delaney A, et al. Very old patients admitted to intensive care in Australia and New Zealand: a multi-centre cohort analysis. Crit Care 2009;13(2):R45. (PMID:19335921)

13. Roch A, Wiramus S, Pauly V, et al. Longterm outcome in medical patients aged 80 or over following admission to an intensive care unit. Crit Care 2011;15(1):R36. (PMID: 21261976).

14. Orsini J, Butala A, Salomon S, et al. Prognostic factors associated with adverse outcome among critically ill elderly patients admitted to the intensive care unit. Geriatr Gerontol Int 2015;15(7):889-94. (PMID:25255733).

15. Sodhi K, Kumar MS, Shrivastava A, Bansal N. Do Intensive Care Units treatment modalities predict mortality in geriatric patients: An observational study 
from an Indian Intensive Care Units. Ind J Crit Care Med 2014;18(12):789-95. (PMID: 25538413).

16. Van Den Noortgate $N$, Vogelaers D, Afschrift $M$, Colardyn F. Intensive care for very elderly patients: Outcome and risk factors for in-hospital mortality. Age Ageing 1999;28(3):253-6. (PMID:10475859). 